Farum

Sociológico

\section{Forum Sociológico}

Série II

$24 \mid 2014$

Circulação de saberes e desafios em saúde

\title{
Desafios atuais para a pesquisa qualitativa: Considerações no cenário da saúde coletiva brasileira
}

Challenges for qualitative research: contributions from the Brazilian collective health field

\section{Maria Lúcia Magalhães Bosi}

\section{OpenEdition}

\section{Journals}

\section{Edição electrónica}

URL: https://journals.openedition.org/sociologico/996

DOI: 10.4000/sociologico.996

ISSN: 2182-7427

\section{Editora}

CICS.NOVA - Centro Interdisciplinar de Ciências Sociais da Universidade Nova de Lisboa

\section{Edição impressa}

Paginação: 19-26

ISSN: 0872-8380

\section{Refêrencia eletrónica}

Maria Lúcia Magalhães Bosi, «Desafios atuais para a pesquisa qualitativa: Considerações no cenário da saúde coletiva brasileira », Forum Sociológico [Online], 24 | 2014, posto online no dia 01 novembro 2014, consultado o 29 março 2022. URL: http://journals.openedition.org/sociologico/996 ; DOI: https://doi.org/10.4000/sociologico.996

Este documento foi criado de forma automática no dia 29 março 2022

(c) CICS.NOVA 


\section{Desafios atuais para a pesquisa qualitativa: Considerações no cenário da saúde coletiva brasileira ${ }^{1}$}

Challenges for qualitative research: contributions from the Brazilian collective health field

Maria Lúcia Magalhães Bosi

\section{Introdução}

1 Este artigo desdobra reflexões desenvolvidas em outras publicações, notadamente a discussão desenvolvida em um artigo recentemente publicado, voltado ao objeto aqui focalizado ${ }^{2}$. Ciente dos riscos impostos pelo limite de espaço, a proposta aqui é recuperar o panorama que gradualmente veio se descortinando ao longo de uma extensa e intensa práxis acadêmica, com vistas a compartilhar algumas reflexões e inquietações acerca de certos desafios que se impõem ao enfoque qualitativo. Cabe assinalar que a discussão se refere ao contexto científico brasileiro e, mais especificamente, ao campo da Saúde Coletiva.

2 No que concerne ao que denomino Pesquisa Qualitativa (PQ), reitero a acepção já tratada em publicações anteriores (Uchimura e Bosi, 2002; Bosi e Uchimura, 2002), nas quais demarcamos qualidade/qualitativo(a) na interface com a subjetividade, salientando que alguns desafios adiante examinados dizem respeito ao plano conceitual e a ele retornarei.

Quanto à Saúde Coletiva $(\mathrm{SC})$, é preciso reconhecê-la, sobretudo, como um campo, conceito que, referido ao espaço da ciência, encontra uma definição estratégica na teoria dos campos sociais transversal à obra de Pierre Bourdieu, na qual campo corresponde a um "espaço de luta concorrencial no qual o que está em jogo são os monopólios da autoridade científica [...] e da competência científica [...] socialmente outorgadas" (Bourdieu, 2003). Ao lançar mão desse conceito, pretendo marcar distância da noção de 
"área de conhecimento". Isso porque, longe de prevalecer no campo científico uma lógica imanente de desenvolvimento científico por superação de paradigmas (Khun, 1978), conforme o termo área pode sugerir, tal economia interna é analisada de forma bastante lúcida por Bourdieu (2003: 124), quando afirma serem reciprocamente os conflitos epistemológicos inseparavelmente conflitos políticos. "Campo" é, portanto, um conceito que devolve ao espaço científico sua dimensão política.

Quanto às tentativas de definir $\mathrm{SC}$, uma consulta aos esforços realizados por vários autores nos leva a constatar um consenso quanto a demarcá-la, a um só tempo, como campo de conhecimento e âmbito de práticas (Paim, 2006; Campos, 2000; Nunes, 2009); portanto, como campo e movimento. Sua constituição interna se fundamenta em três núcleos de saberes (Bosi e Prado, 2011) que correspondem à Epidemiologia; à parcela das Ciências Humanas e Sociais (CHS) incorporadas ao campo e ao núcleo que, sob várias denominações, se ocupa das Políticas, da Planificação e da Gestão de Sistemas de Saúde.

Cabe assinalar que a Epidemiologia persiste como o núcleo hegemônico nesse campo, aspecto que, conforme examinado adiante, subjaz a vários desafios com que se depara o enfoque qualitativo nesse campo.

6 Muitos elementos já vêm sendo interrogados por diversos autores no debate sobre o referencial das CHS na Saúde Coletiva. Contudo, o tema ainda demanda análises que possam subsidiar reflexões e ações, em especial no que tange especificamente à pesquisa qualitativa. A presente discussão se origina, antes de tudo, no desconforto ante os desafios que procurarei assinalar e no desejo de contribuir para o aprofundamento desse debate na SC, fortalecendo seu projeto original que, conforme apontado, se constrói como campo e movimento.

\section{Desafios contemporâneos}

7 Transitarei agora para o objeto central deste artigo, voltando-me aos desafios que se apresentam no panorama atual do enfoque qualitativo na SC. Cabe ressalvar que, na impossibilidade de esgotá-los nesta breve análise, focalizarei aqueles cujos desfechos considero mais decisivos para a consolidação do referido enfoque nesse espaço específico.

Como estratégia de exposição, sistematizarei a discussão em tópicos sequenciais. Contudo, fiel a uma aproximação complexa ou sistêmica, reconheço, de antemão, a presença de várias conexões entre os mesmos, ainda que os tópicos tratados se situem em planos distintos. Assim, na discussão que se segue, observa-se um deslizamento progressivo do plano conceitual ao nível das práticas em SC. Partindo de questões situadas no que aqui denomino plano epistêmico ou teórico-conceitual, focalizarei, gradualmente: aspectos éticos e operacionais da PQ; o lugar reservado a esse enfoque no campo científico; o plano da formação, culminando em desafios relacionados à transferência de conhecimento com vistas à consolidação das reformas já em curso ou pretendidas para o setor.

\section{Pesquisa qualitativa: do que estamos falando?}

9 Ao inaugurar esta explanação com uma definição genérica de pesquisa qualitativa, fiz a ressalva de que seria preciso retornar a este tema e reexaminá-lo. Inicio comentando 
algumas posturas, ainda muito generalizadas, que se polarizam no que qualifico, por um lado, como confusão e, no outro polo, reducionismo. Exemplificarei com apenas três problemas que ilustram tais posturas e remetem ao: emprego dos conceitos; uso indiscriminado de termos e, por fim, ao debate (por vezes, embate) entre os enfoques qualitativo e quantitativo. Sumarizo a seguir aspectos centrais a cada um deles.

Quanto ao emprego dos conceitos, iniciarei aludindo, uma vez mais, ao verbete qualidade, estendendo-se ao que se concebe como qualitativo. Não me alongarei neste assunto, haja vista, em artigo publicado há uma década ( Uchimura e Bosi, 2002) já termos nos detido nesses conceitos, no intuito de apontar alguns subsídios voltados à sua demarcação, discussão desdobrada posteriormente em outros textos (Bosi e Uchimura, 2007; Bosi e Martínez, 2004). Entretanto, decorridos alguns anos desde essas publicações, prossigo constatando problemas no emprego dos referidos conceitos, o que me força a reiterar que na gênese dos equívocos reside a presença do que denominamos na discussão empreendida tensão semântica, multidimensionalidade intrínseca e multidimensionalidade extrínseca inerentes ao conceito (Uchimura e Bosi, 2002).

11 Passando ao segundo problema assinalado, atinente ao uso indiscriminado de termos, noções e conceitos, observam-se problemas quanto ao emprego intercambiável de método, técnica, análise, dentre outros, expressando falta de clareza no que tange ao nível a que cada um faz referência (Tesch, 1995; Mercado, Lizardi et al., 2002) Conforme assinalamos em outros momentos, "[...]. A freqüente redução de um plano a outro possibilita [...] que o (mero) emprego substitua a necessária "postura qualitativa», ou seja, um fundamento epistemológico, no qual as técnicas façam sentido - um método - e do qual as mesmas se originem" (Martínez e Bosi, 2004: 33-34).

Finalizando com o terceiro aspecto destacado neste primeiro desafio, cabe comentar as disputas qualitativo-quantitativo, já amplamente analisadas na literatura (Creswell, 1994; 2007b; Denzin, 2009; Conde, 2002). Na práxis da pesquisa e nos debates sobre o tema na SC, observa-se que tais paradigmas ora são considerados enfoques alternativos para uma mesma questão, ora paradigmas em disputa pelo status de approach superior.

Uma terceira posição, na polaridade oposta, assume uma harmonia paradigmática olvidando as descontinuidades e rupturas entre os mesmos. Tal como examinado de forma mais detalhada em outro texto (Bosi, 2012a), defendo que, em cada uma dessas leituras ou polarizações, ocultam-se graves lacunas de compreensão no que concerne à multidimensionalidade do fenômeno saúde, gerando obstáculos para a necessária interdisciplinaridade no campo.

\section{Taxonomias, nomenclaturas, vertentes}

14 Na continuidade do que acabo de examinar, tratarei de forma mais específica outro desafio conceitual, referente à questão das taxonomias e terminologias utilizadas pelos pesquisadores qualitativos. Ao adentrar nessa discussão, vejo-me transportada ao mito bíblico da torre de Babel, narrativa bastante conhecida do Antigo Testamento (Gênesis, 2005:11). Dentre os significados desse intrigante mito bíblico, um deles me chama poderosamente a atenção: a alusão à diversidade de idiomas que separa a humanidade que soa como metáfora do que pretendo comentar neste tópico. 
há algum tempo - provavelmente se sentirá como um dos discípulos de Noé que, ao subir a Torre de Babel, se vê em meio a uma confusão de idiomas. É fato que a $\mathrm{PQ}$, mais ainda na SC, é marcada pela interdisciplinaridade, nutrida por vários referenciais e por conceitos complexos e interconectados, oriundos de teorias densas, de vários alcances. Contudo, cabe reconhecer serem necessários investimentos e uma cuidadosa reflexão sobre o assunto, sobretudo no que tange aos seus efeitos na interdisciplinaridade pretendida por essa tradição. Não obstante, reflexões e sobretudo proposições acerca da terminologia nesse enfoque são ainda escassas na literatura, ainda que se localizem alguns registros ( Mercado, Lizardi et al., 2002; Patton, 2002). Dentre as várias indagações a serem feitas destaco uma que me parece pertinente: em que medida essa pluralidade de idiomas se deve efetivamente à diversidade epistemológica e disciplinar que permeia a área? Cabe reconhecer que a diversidade disciplinar constitutiva desse enfoque impede advogar por uma codificação homogênea que neutralizaria sua origem interdisciplinar. Contudo, são preocupantes certas tendências que, no limite, levariam a admitir tantos modelos quantos investigadores existentes, resultando na multiplicação ad infinitum de vertentes e nomenclaturas particulares, como se estivéssemos sempre partindo do zero ou fundando escolas. Será mesmo justificável tal procedimento ou deveríamos investir na busca de outras alternativas que viessem a facilitar o diálogo não apenas inter, mas intra-enfoques na SC?

16 No que concerne às taxonomias (e paradigmas) em pesquisa qualitativa, a exemplo daqueles propostos por autores como Denzin e Lincoln (2000), Creswell (1994; 2007a), Morse e Field (1995), a questão não consiste apenas na dificuldade de "enquadre" nesses tipos-ideais, mas, na própria separação, por vezes, demasiado estanque, entre as modalidades. Esse aspecto nos motivou a sugerir, em outro texto, caracterizações (em lugar de paradigmas) de tipo fuzzy, ou seja, mais transicionais (Martínez e Bosi, 2004). Isso porque, na nossa experiência, grosso modo, as pesquisas em SC se enquadram no entre dessas tipologias, ainda que nem sempre isso se mostre bem assimilado.

17 Partindo dessa assertiva que sintetiza o âmago da questão, cabe indagar: como no interior da tradição qualitativa vêm se legitimando "novas vertentes" e se consagrando nomenclaturas? Confundir rótulos com vertentes fragiliza a totalidade do enfoque e seu potencial - consistindo no que denominarei, à falta de uma melhor expressão, pseudoescolas.

18 Não seria o caso de, no interior desse enfoque, investirmos em estratégias que auxiliem a identificar idiomas comuns, ainda que respeitando sotaques, entonações e certas singularidades, em lugar de seguirmos criando idiomas inteligíveis apenas em círculos por vezes bastante restritos? Se seguirmos nessa direção, aprofundaremos uma confusão de idiomas que impedirá o diálogo como no mito bíblico.

\section{Incorporação de novas contribuições e as "alianças" entre saberes}

Com efeito, o caráter complexo (Morin, 2004) dos objetos de que se ocupam as pesquisas qualitativas desafia as vertentes atuais e convida a novas orientações e à formulação de novas técnicas de investigação. Quanto a isso, e concordando com o que predomina na 
literatura (Patton, 2002; Grbich, 2007),

há que preservar a flexibilidade permitindo a necessária adaptação e recriação de modelos. concerne às terminologias e taxonomias, já que a tarefa não se reduz a (re)criar novos rótulos mas vertentes inovadoras, ou seja, novas construções, devidamente fundamentadas. A flexibilidade aqui defendida implica o entendimento profundo de que enfoques se vinculam a tradições epistemológicas, teorias e princípios que precisam ser identificados, exigindo elevado investimento nessa direção, de modo a que a opção possa ser adequadamente justificada e operacionalizada.

21 Feita a ressalva, o momento demanda, mais do que nunca, inovação, convidando não apenas à interdisciplinaridade, mas à inter(trans)culturalidade. Ao me referir à interculturalidade (Santos e Meneses, 2010) e não somente à interdisciplinaridade, pretendo operar um deslocamento nesta discussão do âmbito científico estrito, ampliando-a para outras arenas sociais. Nestas são produzidos, se não conhecimentos disciplinados pela racionalidade científica moderna, saberes "nativos" que precisam formar alianças, religarem-se (Morin, 2002) a outros, processo de importância primordial para o campo da SC. as artes - cinema, teatro, fotografia, pintura, literatura, conforme já vem se dando em muitos espaços, ainda que o tema seja polêmico e se localizem resistências (Denzin, 2009). Não obstante certas dificuldades, $h$ á que combinar aprendizado científico com o desenvolvimento de outras dimensões artística, intuitiva, dialógica, unindo o que a modernidade divorciou (Luz, 1988). Mas, cuidando das "aventuras". Portanto, o que postulo é ousadia com rigor.

Ao defender o rigor, a despeito das críticas que poderei sofrer em um momento que clama por desconstruções, faço-o assumindo uma clara posição: o projeto e o movimento da pesquisa qualitativa, aqui referido ao âmbito da SC, não podem prescindir de uma reflexão acerca da qualidade do que vem sendo produzido. Quanto a isso, a literatura especializada é prolífera no que tange a dimensões e respectivas estratégias de avaliação da qualidade de pesquisas qualitativas, tendendo ao reconhecimento consensual de que a conquista desses padrões é, tal como aqui demarcamos, um importante desafio. Sobretudo quando o enfoque vem ganhando cada vez mais espaço nos periódicos científicos na SC. Mas o que significa pesquisa qualitativa de "qualidade"?

Sem desmerecer (e tampouco excluir) as importantes contribuições que a literatura vem aportando acerca dos parâmetros técnicos a serem alcançados, mas levando em conta as considerações feitas quando da discussão do que aqui consideramos postura qualitativa, sustento que a pesquisa qualitativa de qualidade será aquela que apresentar coerência e consistência simultaneamente em três níveis: ontológico, metodológico e ético. Tal tríade significa, antes de tudo, delimitar claramente um objeto cuja natureza se coadune com o enfoque, empregando conceitos adequados às vertentes eleitas, reconhecendo vínculos ante as distintas tradições, adotando modelos abertos de pesquisa e procedimentos indutivos, mantendo a reflexividade como princípio orientador (Green e Thorogood, 2009). 
Se problemas relacionados às técnicas demandam teorização - são, portanto, problemas teóricos -, há também que considerar problemas éticos como problemas teóricos, ou seja, inserir preocupações éticas como item de rigor (Guillemin e Gillam, 2004) na produção negociada de evidências - expressão que emprego em lugar de coleta de dados, por entender esta última, não obstante sua ampla utilização por parte de pesquisadores qualitativos, como inadequada às premissas do enfoque.

Finalmente, e assumindo o entendimento de que a comunicação dos resultados é parte primordial da pesquisa e possui claras interfaces com a qualidade da produção, há que cuidar das várias questões relativas à publicação de resultados que remetem ao já assinalado acerca da tradução dos "achados" e do rigor metodológico. Para além disso, introduz no debate a consideração dos veículos (periódicos, livros e outros) e respectivas políticas editoriais, bem como a hierarquia adotada na economia interna do campo SC, introduzindo dentre outras indagações as que seguem: como sob o regime de produtividade atual se situam os veículos que disseminam pesquisas qualitativas? Como se caracteriza a velocidade de produção nessa tradição? Que constrangimentos se impõem ao enfoque qualitativo tendo em vista os ritmos de produção, a divisão do trabalho e as características das autorias?

7 Tais questões, dentre outras, analisadas de forma mais detida em uma recente publicação (Bosi, 2012b) e que escapam aos limites deste texto, nos levam, neste ponto do debate, a valorizar o processo de construção da ciência e as circunstâncias que cercam a PQ no chão de fábrica do campo científico, mais precisamente na SC, cenário da análise em curso.

Parece-me oportuna esta alusão, uma vez que, a despeito do discurso com que se reveste a SC brasileira e dos compromissos históricos que a marcam como movimento, o modelo de avaliação científica adotado nesse campo também tem sido aquele em que a relevância social nem sempre conta ante o peso de outros parâmetros. Por conseguinte, não se valorizam devidamente produtos voltados para o sistema de saúde, aprofundando a dificuldade de apropriação das pesquisas pela sociedade, ainda que financiadas com recursos públicos.

Isso deve merecer uma rigorosa análise, antes de nos apressarmos a afirmar um crescimento exponencial da produção científica no campo, ou da "ciência brasileira", enquanto alguns pesquisadores vêm alertando para a falácia desse modelo comentando sua lógica interna, e sua nocividade evidenciada no desencantamento do trabalho científico e na impossibilidade de uma dedicação apaixonada (Weber, 1982), desdobrando-se no sofrimento e adoecimento dos pesquisadores e dos alunos (Luz, 2005; Rocha-e-Silva, 2009), muitas vezes, em um contexto do quanto mais, melhor; não importa do que (ou a que preço).

Contudo, se na polaridade campo é esta a visão de mundo, nas palavras de ordem do movimento sanitário e no ideário do sistema defendido pela $\mathrm{SC}$ como movimento, justiça e equidade figuram como princípios; esse paradoxo é o que mais me preocupa e quanto a isso volto a sublinhar: a adesão à atual política de produtividade vem criando um abismo e uma contradição entre as esferas da SC como produção do conhecimento e como movimento, uma vez que na primeira esfera se operacionaliza precisamente o que contradiz a segunda, tendo como protagonistas atores do próprio campo, consoante às normas de conformação dos comitês. 
31 Ainda assim, cabe insistir no fato de, sendo a ciência construção humana, portanto aberta e inacabada, nada nos conduz à fatalidade de um destino já dado; ao contrário, acreditamos na possibilidade de novos acordos na saúde coletiva, como, aliás, vem ocorrendo, no que concerne à construção de algumas agendas importantes, dentre elas a que orienta a avaliação da pós-graduação, ainda que não se tenha chegado a um modelo que responda plenamente às várias dimensões e à diversidade que compõe a área.

Para além do assinalado, a reversão depende da formação de quadros, em escala e grau de maturidade que possam impactar as agendas no campo científico: um monumental desafio para quem protagoniza o ensino deste enfoque na SC, conforme passamos a expor.

\section{Formação de pesquisadores qualitativos: como expandir sem perder a qualidade?}

Ao iniciar este tópico, uma primeira constatação é a lacuna no que concerne a discussões de avanços e dificuldades enfrentadas no ensino desse enfoque (Martínez, Bosi et al., 2005) e, mais precisamente, a inexistência quase absoluta de literatura voltada ao tema do ensino da PQ no âmbito da saúde (coletiva).

Corroborando o que acabamos de afirmar, cabe registrar a ausência deste capítulo nas obras de referência - compêndios ou handbooks - relativas à $\mathrm{PQ}$, mesmo em âmbitos externos à SC. Uma busca nas obras clássicas e mais referidas (Tesch, 1995; Denzin \& Lincoln, 2000; Patton, 2002; Creswell, 1994; 2007a; Silverman e Marvasti, 2008) nos revela que, a despeito de aspectos não relativos ao método em sentido estrito, encontrarem espaço nesses textos englobando: "como publicar", "como construir um projeto", "como avaliar a qualidade de produtos" dentre outros temas, nada se fala sobre "como ensinar PQ". Contudo, conforme já aludido, o tema merece investimentos e não pode ser excluído em uma discussão dirigida aos desafios atuais do enfoque qualitativo.

Um primeiro aspecto a destacar - e que não surpreende - é que o modelo formador conflui em vários aspectos (até porque se vinculam) para o que acabamos de discutir acerca do modo de produção do conhecimento, o que conduz a mais uma indagação: quais as chances de reversão da atual equação entre o ensino deste enfoque e dos demais, no espaço da SC?

De inicio, é preciso observar que os estudantes ingressos nos cursos da saúde coletiva provêm de distintas formações na saúde e outros campos, nos quais, grosso modo, o ensino do enfoque qualitativo é ausente ou muito rudimentar. Para os docentes dedicados à formação nesse enfoque, isso implica responder a uma série diversificada de demandas, muitas delas de caráter instrumental. Outro fator importante é a formação e a bagagem epistemológica não apenas de quem chega aos cursos mas, o que é mais preocupante, dos próprios docentes, dado não contarmos no Brasil com formações estruturadas em PQSC como ocorre em outros âmbitos (Martínez, Bosi et al., 2008).

Imersos como estamos em uma cultura da quantidade, à qual desde cedo nos acostumamos em nossos processos de socialização primária (Berger e Luckmann, 2011), conteúdos voltados à mensuração, bem como aqueles que fundam o modelo biomédico, 
nos são transmitidos desde o ensino fundamental, garantindo, assim, as bases das pesquisas nas tradições quantitativa e experimental. Em contrapartida, quais conteúdos são valorizados ao longo dos ciclos pré-universitários como base para uma postura qualitativa (Bosi e Martínez, 2004)? E em nível de graduação, qual curso na saúde oferece esta base? A resposta me parece clara: Quase nada se aporta no que concerne aos fundamentos do enfoque qualitativo em saúde (coletiva). Mais que isso, o modelo formador neutraliza até mesmo a subjetividade dos educandos e os avalia mediante números. E as pós-graduações, seja na SC, seja em outros campos, não podem suprir essa lacuna monumental que abrange conteúdos, habilidades e valores que deveriam ser desenvolvidos desde cedo, muito antes do ingresso na formação superior.

Assim, o sistema favorece a reprodução e expansão de um contingente expressivo de pesquisadores aptos a operacionalizar outras tradições, sendo um extraordinário desafio formar um doutor no enfoque qualitativo capaz de produzir efeitos no campo, ou seja, influenciar os mecanismos, agendas e processos específicos que operam na produção de conhecimento e nas definições relativas à pesquisa e sua difusão (ou seja, na distribuição do capital cientifico, econômico e social) no campo SC.

Ao examinarmos, em outro espaço, o processo de produção do conhecimento no regime atual, marcado pela produtividade (Bosi, 2012b), alertamos para certos paradoxos na SC, e certas contradições geradas pelo ritmo veloz, como a desumanização das práticas sociais e a redução de relações entre pessoas a relações Eu-Isso (Buber, 2009); ainda quando as novas tecnologias confundem fluxo de informação com comunicação dialógica. Pensamos que, dentre outros desfechos, alguns deles já aqui mencionados, essa intensificação da produtividade se faz à custa da dedicação ao ensino, sobretudo em sistemas de avaliação (como vem se tornando o sistema de avaliação acadêmica no Brasil) para o qual ensinar não é ser produtivo. Diante do exposto: Será que os valores que compõem o ideário das reformas na saúde confluem para o modelo de ensino em SC ou vêm se reproduzindo hegemonicamente, também nesse campo, o formato tradicional?

Enquanto as respostas a questões como esta apontarem que o desafio da formação ainda persiste, conforme acredito ser o caso em tela, será difícil refundar o sistema e as práticas de saúde, haja vista buscarmos torná-los o que ainda não somos. No que concerne ao enfoque qualitativo, sem profissionais adequadamente formados, como fica o desafio não só de construir, mas, sobretudo, de transferir os achados da PQ para os sistemas de saúde, alicerçando dimensões centrais das reformas no setor?

\section{Para concluir. acerca da apropriação social dos resultados das pesquisas qualitativas em saúde coletiva}

41 Na etapa atual de consolidação da Reforma Sanitária Brasileira (RSB), a qualificação da atenção básica entendida como estratégia central de reorganização do sistema se situa no centro dos debates. Humanização, equidade e integralidade, dentre outros conceitos-força que circulam no discurso da SC e da RSB, implicam em incluir a qualidade a partir de uma acepção pluridimensional, qualitativa e participativa. Neste ponto, parece-nos extremamente oportuna a advertência feita por Morin (2004: 54) no trecho que segue: "[...] quanto mais os problemas se tornam multidimensionais, maior a 
incapacidade de pensar sua multidimensionalidade; quanto mais a crise progride, mais progride a incapacidade de pensar a crise".

Com efeito, por diversas vezes, experienciamos dificuldades de operacionalizar modelos de pesquisa multidimensionais combinando dimensões qualitativas com estudos quantitativos, pelo fato de os modelos tradicionais - ainda que não deem conta da complexidade dos objetos, se mostrarem mais simples e "objetivos", além de se coadunarem com o "ritmo veloz" e outros aspectos da cultura acadêmica a que já aludimos. Tal situação, consoante Morin, (2004) obriga a "[...] reduzir o complexo ao simples, isto é, a separar o que está ligado [...] sua visão determinista, mecanicista, quantitativa, formalista ignora, oculta ou dilui tudo o que é subjetivo, afetivo, livre e criador" (grifo do autor).

Os excertos acima se aplicam ao desencontro entre o que dispomos de estoque de conhecimento na Saúde (Coletiva) e o que vimos assistindo na recriação de modelos adequados ao cenário atual na inventividade necessária (Flick e Salomon, 2011) ao redirecionamento do discurso da reforma que não pode se repetir como um mantra por não se tratar de doutrina (Morin, 2010) mas um texto aberto a recriações. Em que medida esse discurso que até pode ter dado conta dos desafios centrais quando da sua emergência como movimento precisa se atualizar em consonância com os complexos processos que respondem pelos desfechos atuais? Desfechos estes repetidamente mensurados, mas ainda insuficientemente compreendidos na diversidade dos territórios e grupos que compõem um país.

Precisamos inocular o campo da Saúde Coletiva Humana, com o que é subjetivo, afetivo, livre e criador - e este é o aporte primordial do enfoque qualitativo cuja contribuição já abrange a quase totalidade dos objetos e temas da SC (Mercado, Gastaldo et al., 2002; Martínez, Gastaldo et al., 2008; Morin, 2010). Mas, para além dessas constatações atinentes à expressividade dos aportes da $\mathrm{PQ}$, nem sempre visualizados, precisamos pensar formas de impactar não apenas o campo científico, mas democratizar o conhecimento. Assim, cabe interrogar: $O$ que vem sendo feito com os resultados das pesquisas qualitativas? Quais as eventuais barreiras e qual agenda para ultrapassar os obstáculos? Tais questões nos reconduzem a vários elementos comentados em tópicos anteriores, reforçando a necessidade de uma visão sistêmica (complexa) na consideração dos desafios aqui discutidos cuja sinergia não pode ser esquecida.

A questão acerca do que vem sendo feito com os resultados pede um posicionamento quanto à propriedade dos mesmos e seus usos, levando-nos a um distanciamento tanto de visões utilitaristas como de posições indiferentes à sua utilização, como se a finalidade do saber produzido fosse repousar em volumes nas prateleiras das universidades ou nos curricula vitae dos pesquisadores. A questão da apropriação social não é meramente técnica; é ético-política.

o direito ao conhecimento integra a cidadania; o monopólio da ciência por parte dos experts e técnicos regride a competência democrática (Morin, 2004), favorecendo, conforme se observa nos dias atuais, a expansão de comportamentos vinculados a interesses de segmentos que controlam meios poderosos de disseminação de discursos, notadamente a mídia.

Circunscrevendo o tema à SC, são amplamente mencionados na literatura os aportes do enfoque qualitativo ao campo, o que nos dispensa de reiterá-los. Mas o que deve ser transferido? Como? Por quem? Percorrendo as questões acima, é evidente que devemos 
transferir todo o conhecimento que seja útil à elucidação e superação dos problemas sócio-sanitários. Na PQ impõe-se amplo acesso aos resultados e o direcionamento da investigação, aproximando academia, serviços, gestão e comunidade.

Da mesma forma e, talvez, de modo ainda mais refinado que para os demais enfoques, há que ter habilidades para entender, contextualizar e traduzir os resultados das pesquisas qualitativas que, envolvendo interpretações e distintos pontos de vista, contradições e mediações, não podem ser reduzidos a prescrições e a relações lineares. Os problemas surgem quando esbarramos na escassez de pessoal capacitado tanto para pesquisa como para sua aplicação (quem), bem como na adequação e alcance dos veículos (como).

Quando da análise do processo de produção do conhecimento, discutimos a necessária articulação com todas as formas de linguagem, para as quais as pesquisas podem aportar conteúdo. Entretanto, podemos afirmar que ainda estamos engatinhando no âmbito da difusão de resultados na saúde; também aqui, a produtividade e acumulação do capital científico restringem sobremaneira as possibilidades de recriar formas de divulgação (Bosi, 2012b).

Ainda assim, suspeito que oportunidades que vêm surpreendendo em linhas mais abertas ao livre pensar, solidamente alicerçadas na produção de renomados pesquisadores no domínio da $\mathrm{PQ}$, podem fazer emergir novos protagonismos na academia, nos serviços, nos vários grupos e comunidades que interagem no campo SC.

51 Se é certo que o momento atual nos confronta inexoravelmente e cada vez com mais força com os desafios da complexidade, então talvez nessa crise se encontre a oportunidade de: tecer esperanças em uma (re)valoração da ciência e da pesquisa; sonhar com novas alianças entre enfoques e saberes, com o resgate da alegria e do encantamento com o fazer científico apaixonado, longe das amarras de uma produtividade muitas vezes estéril, adoecedora e alienante. Um projeto que nos conduza a um novo tempo no qual os desafios aqui assinalados não sejam mais contemporâneos.

\section{BIBLIOGRAFIA}

BERGER, P e T. Luckmann (2011), A construção social da realidade, Petrópolis, Vozes, 33. a ed.

BOSI, M. L. M. e F. J. M. Martínez (2004) (orgs.), Pesquisa Qualitativa de Serviços de Saúde, Petrópolis, Ed. Vozes.

BOSI, M. L. M e K. Y. Uchimura (2007), “Avaliação da Qualidade ou Avaliação Qualitativa da Atenção? Elementos para uma demarcação conceitual”, in Revista de Saúde Pública/Journal of Public Health, v. 41, pp. 150-153.

BOSI, M. L. M e S. D. Prado (2011), "O Campo da Alimentação e Nutrição em Saúde Coletiva: constituição, contornos e estatuto científico”, Ciência e Saúde Coletiva (Impresso), v. 16, pp. 7-17. 
BOSI, M. L. M. (2012a), “Pesquisa Qualitativa em Saúde Coletiva: Panorama e Desafios”, in Ciência e Saúde Coletiva (Impresso), v. 17, pp. 575-586.

BOSI, M. L. M (2012b), "Produtivismo e avaliação acadêmica na Saúde Coletiva brasileira: desafios para a pesquisa em Ciências Humanas e Sociais”, Cadernos de Saúde Pública, 28 (12), pp. 2387-2392. BOURDIEU, P. (2003), “O campo científico”, in R. Ortiz (org.), Pierre Bourdieu, São Paulo, Ática. BUBER, M. (2009), Do diálogo e do dialógico, São Paulo, Perspectiva.

CAMPOS, G. W. S. (2000), "Saúde pública e saúde coletiva: campo e núcleo de saberes e práticas”, Ciência \& Saúde Coletiva, 5 (2), pp. 219-230.

CONDE, F. (2002), "Encuentros y desencuentros entre la perspectiva cualitativa y la cuantitativa en la historia de la medicina”, Revista Española Salud Publica, v. 76, n.ํ5, setembro/outubro.

CRESWELL, J. W. (1994), Research Design: Qualitative, Quantitative and Mixed Methods Approaches, Londres, Sage.

CRESWELL, J. W. (2007a), Qualitative Inquiry \& Research Design: Choosing among five approaches, Londres, Sage.

CRESWELL, J. W. e V. P. Clark (2007b), Designing and conducting mixed methods research, California, Sage.

DENZIN, N. K. e Y. S. Lincoln (2000), The Sage Handbook of Qualitative Research, Califórnia, Sage.

DENZIN, N. K. (2009), “Apocalypse Now: overcoming resistance to qualitative inquiry”, in International Review of Qualitative Research, 2 (2), pp. 331-343.

FLICK, U. e A. Salomon (2011), “Mixing Methods, Triangulation and Integrated Research: Challenges for Qualitative Research in a World of Crisis", in N. Denzin e M. D. Giardina, Qualitative Inquiry and Global Crisis, Thousand Oaks, Sage.

Gênesis (11: 1-9) (2005), in Bíblia Sagrada. Nova tradução na linguagem de hoje, São Paulo, Paulinas Editora, p. 11.

GRBICH, C. (2007), Qualitative Data Analysis: An Introduction, Thousand Oaks, Sage.

GREEN, J. e N. Thorogood (2009), Qualitative methods for health research, Thousand Oaks, Sage.

GUILLEMIN, M. e L. Gillam (2004), "Ethics, reflexivity, and «ethically important moments» in research", Qualitative Inquiry, Thousand Oaks, v. 10, n. 2, pp. 261-280.

KHUN, T. (1978), A estrutura das revoluções científicas,São Paulo, Perspectiva.

LUZ, M. T. (1988), Natural, racional, social: razão médica e racionalidade científica moderna, Rio de Janeiro, Campus.

LUZ, M. T. (2005), "Prometeu acorrentado: análise sociológica da categoria produtividade e as condições atuais da vida acadêmica", Physis, v. 15, n.. 1, pp. 39-57.

MARTÍNEZ, F. J. M. e M. L. M. Bosi (2004), “Pesquisa Qualitativa: Notas para um Debate”, in M. L. M. Bosi e F. J. Mercado (orgs.), Pesquisa Qualitativa de Serviços de Saúde, Petrópolis, Editora Vozes, pp. 23-72.

MARTÍNEZ, F. J. M.; M. L. M. Bosi et al. (2005), “La Enseñanza de la Investigación Cualitativa en Salud. Voces desde Iberoamérica”, in Salud Colectiva, La Plata, 1 (1), pp. 97-116, janeiro-abril.

MARTÍNEZ, F. J. M.; D. Gastaldo et al. (2008), "Health Policy and Programs Evaluative Research for Social Change”, in Forum: Qualitative Social Research Sozialforschung, v. 9, pp. 19-26. 
MERCADO, F. J.; A. Lizardi et al. (2002), “Investigación Cualitativa en Salud em América Latina. Una aproximación", in F. J. Mercado e D. Gastaldo et al., Paradigmas y Diseños de La Investigación Cualitativa em Salud, Guadalajara, Ed. Universidade de Guadalajara, pp. 133-158.

MERCADO, F. J.; D. Gastaldo et al. (2002), Paradigmas y diseños de la Investigación Cualitativa en salud. Una antologia Iberoamericana, Guadalajara, Universidad de Guadalajara/Universidad Autónoma de Nuevo León.

MORIN, E. (2002), A religação dos saberes. O desafio do século XXI, Rio de Janeiro, Bertrand do Brasil.

MORIN, E. (2004), A cabeça bem-feita, Rio de Janeiro, Bertrand do Brasil.

MORIN, E. (2010), Ciência com consciência, Rio de Janeiro, Bertrand do Brasil.

MORSE, J. e A. Field (1995), Qualitative Research Methods for Health Professionals, Thousand Oaks, Sage.

NUNES, E. D. (2009), "Saúde coletiva: uma história recente de um passado remoto", in G. W. S. Campos e M. C. S. Minayo et al., Tratado de Saúde Coletiva, São Paulo/Hucitec, co-edição: Rio de Janeiro, Ed. Fiocruz, pp. 295-315.

PAIM, J. S. (2006), Desafios para a saúde coletiva no século XXI, Salvador, EDUFBA.

PATTON, M. Q. (2002), Qualitative Research \& Evaluation Methods, Londres, Sage.

ROCHA-E-SILVA, M. (2009), “O Novo Qualis, que não tem nada a ver com a ciência do Brasil: carta aberta ao presidente da CAPES”, Clinics, v. 64, n.ำ 8, pp. 721-724.

SANTOS, B. S. e M. P. Meneses (2010) (orgs.), Epistemologias do Sul,São Paulo, Cortez.

SILVERMAN, D. e A. Marvasti (2008), Doing Qualitative Research: A comprehensive guide, Thousand Oaks, Sage.

TESCH, R. (1995), Qualitative Research. Analysis types \& software tools, Nova Iorque, The Falmer Press.

UCHIMURA, K. Y. e M. L. M. Bosi (2002), "Qualidade e Subjetividade na Avaliação de Programas e Serviços de Saúde” (Medline), Cadernos de Saúde Pública (FIOCRUZ), Rio de Janeiro, v. 18, n. 6, pp. 1561-1569.

WEBER, M. (1982), “A Ciência como vocação”, in M. Weber, Ensaios de Sociologia, Rio de Janeiro, Ed. Guanabara.

\section{NOTAS}

2. Este artigo consiste em uma edição reformulada e sumarizada do manuscrito: BOSI, M. L. M. (2012), "Pesquisa Qualitativa em Saúde Coletiva: Panorama e Desafios", publicado na revista Ciência e Saúde Coletiva (Impresso), v. 17, pp. 575-586. Reformulação autorizada pelos Editores.

1. Comunicação apresentada no V Congresso Ibero-Americano de Pesquisa Qualitativa em Saúde - Circulação de Saberes e Desafios em Saúde, realizado em Lisboa entre 11 e 13 de Outubro de 2012. 


\section{RESUMOS}

Apresenta-se um panorama concernente ao debate atual do enfoque qualitativo referido ao contexto cientifico brasileiro e, mais especificamente, ao campo da saúde coletiva. Para tanto, inicia-se demarcando conceitos centrais à delimitação do objeto, recuperando-se, na sequência, o cenário atual dessa tradição de pesquisa na saúde. Aponta-se um extenso conjunto de desafios situados nos planos epistêmico; ético; operacional, aqui tomados para análise. Evidencia-se que, a despeito da grande expansão verificada e dos aportes à saúde coletiva, o enfoque qualitativo ainda se depara com vários desafios para a sua plena consolidação. Nesse sentido, demanda investimentos internos ao enfoque e, ainda mais fortemente, certas dinâmicas na interface com os demais núcleos que constituem o campo analisado. 0 artigo conclui sinalizando a possibilidade de novos pactos na Saúde Coletiva, tal como vem ocorrendo com outras agendas, com vistas a um modelo de ciência que responda à complexidade do campo.

This article provides an overview regarding the nuclear themes in the debate about the qualitative health research approach, in the Brazilian scientific context and more specifically in the collective health field. The author starts defining some central concepts in the analysis undertaken. Then, examines the current status of this tradition of research, pointing out an extensive set of challenges. The discussion focuses on each one of them, moving between different plans: epistemic, ethical, operational, the training in this approach and its status in the scientific field. The analysis shows that, despite the expansion observed in qualitative research and its contributions to public health, this approach still faces many challenges to consolidate its status. The situation demands dialogue with others approaches which form the core area. The article concludes pointing out the possibility of new pacts in order to build innovations considering the complexity of the collective health field.

\section{ÍNDICE}

Palabras claves: qualitative research, public health, health systems, methodology

Palavras-chave: pesquisa qualitativa, saúde coletiva, sistemas de saúde, metodologia 